\title{
Acral melanocytic nevi in the Polish population: prevalence, clinical characteristics and dermoscopic patterns
}

\author{
Magdalena Wawrzynkiewicz' ${ }^{1}$ Maciej Pastuszczak ${ }^{1}$, Michał Chlebicki², Anna Wojas-Pelc ${ }^{1}$
}

'Department of Dermatology, Jagiellonian University Medical College, Krakow, Poland ${ }^{2}$ Faculty of Philosophy and Sociology, University of Warsaw, Warsaw, Poland

Adv Dermatol Allergol 2019; XXXVI (5): 581-588 DOI: https://doi.org/10.5114/ada.2018.77500

\begin{abstract}
Introduction: Acral melanocytic nevi dermoscopic patterns have been well described in several populations. There have been no prospective studies assessing the prevalence, clinical characteristics and dermoscopic patterns of acral nevi in the Polish population.

Aim: To characterize the prevalence of acral nevi, frequency of dermoscopic patterns, relationships between acral nevi and patients' characteristics.

Material and methods: This was a prospective study conducted in the Dermatological Outpatient Clinic of the University Hospital in Krakow. Study inclusion criteria: presence of nevi on foot soles and/or palms, Caucasian race, Polish origin, and age $\geq 18$ years.

Results: Six hundred and twenty-four acral melanocytic lesions were observed in 287 patients, 174 (60.6\%) women and 113 (39.4\%) men, mean age 43.5 and 42.8 years, respectively. Four hundred and thirty-four (69.6\%) lesions were present on soles, 190 (30.4\%) on palms. No acral melanomas were detected. The following dermoscopic patterns were observed: parallel furrow 262 (42\%), lattice-like 106 (17\%), fibrillar 66 (11\%) and other 190 (30\%). Patients with acral nevi on the soles or both on the palms and soles had a higher number of atypical nevi on the body $(p=0.011)$ and a much higher total body nevi count $(p=0.043)$, when compared to those with acral nevi only on the palms. Conclusions: The study revealed a higher prevalence of acral nevi in the analysed population. A higher number of acral nevi was associated with a higher number of atypical nevi and higher total body nevi count, the risk factors for melanoma. Because of that it is possible to note that a higher number of acral nevi should increase diagnostic alertness.
\end{abstract}

Key words: dermoscopy, acral nevi, dermoscopic patterns, prevalence.

\section{Introduction}

The acral melanocytic nevus is defined as a nevus located on the palmar aspect of the hand or on the soles of the feet. This location results in specific dermoscopic patterns which are not subjected to standard diagnostic schemes used in dermoscopic assessments of nevi in different locations [1, 2]. Prior studies initiated by Saida et al. [1], and then continued by other researchers, introduced descriptions of specific dermoscopic patterns for acral nevi and acral melanomas. Patterns were characterized by indicating benign (parallel furrow, fibrillar, lattice-like and other patterns: homogeneous, globular, reticular, nontypical, transition) or malignant (parallel ridge, irregular diffuse pigmentation, multi-component, and features such as abrupt edges, serrated pattern, peripheral irregular dots and globules, and/or blue-white veil) nature of acral melanocytic lesions [1-7]. In various studies, different prevalence of acral nevi was observed, depending on the ethnic origin of subjects - from $40 \%$ for skin-of-colour patients to $30 \%$ - for non-Hispanic white patients [6]. In the Japanese population, according to studies conducted by Saida et al., melanocytic nevi prevalence on the soles was $8-10 \%$, and melanomas of acral regions reached nearly half of all melanomas diagnosed in this population [1]. In the white population, acral melanoma is rare and constitutes $3.6-7 \%$ of all melanomas, yet it is more frequently diagnosed in advanced

Address for correspondence: Magdalena Wawrzynkiewicz MD, PhD, Department of Dermatology, Jagiellonian University Medical College, 8 Skawinska St, 31-066 Krakow, Poland, phone: +48 600096 115, e-mail: magda.wawrzynkiewicz@gmail.com Received: 25.05.2018, accepted: 14.06.2018. 
stages which results in worse prognosis for patients $[3,8,9]$. So far, there have been no prospective studies assessing the prevalence of acral melanocytic nevi and acral melanoma, their characteristics and dermoscopic patterns in the Polish population.

\section{Aim}

The primary objective of this study was to (1) assess the prevalence of acral nevi in the Polish population, (2) characterize the type of dermoscopic patterns of acral nevi and (3) assess their most common locations. A secondary objective was to analyse the associations between the character of acral nevi and selected demographic and clinical data. The results were subsequently compared to those from other populations.

\section{Material and methods}

This study was approved by the institutional review board of the Jagiellonian University in Krakow, Jagiellonian University Committee of Bioethics (KBET/220/B/2013) and performed in accordance with the Declaration of Helsinki principles.

A prospective study included 713 patients who visited the Pigmented Lesions and Melanoma Clinic at the Department of Dermatology, Jagiellonian University Hospital in Krakow, Poland. Study inclusion criteria consisted of the presence of nevi on foot soles and/or palms (dorsal, subungual locations of palms and feet were excluded), Caucasian race, Polish origin, age above 18 years. Among all 713 patients, 287 fulfilled the inclusion criteria and were further examined.

Patients' demographic and clinical data were collected (such as e.g. age, occupation, skin phototype according to the Fitzpatrick scale). In 287 patients, 624 acral pigmented nevi were found. The diameter, location and dermoscopic pattern of 624 acral pigmented nevi were analysed. Videodermoscopic photos were taken and archived with 30- and 50-fold magnification with FotoFinder Medicam 800HD. Dermoscopic patterns and structures were analysed according to the classification criteria introduced by Saida et al., Malvehy and Puig, Altamura et al. [1-3].

All acral lesions were analysed and classified into one of the following groups: (1) parallel furrow pattern (a pattern with linear pigmentation parallel to the skin markings); (2) lattice-like pattern (pigmentation follows and crosses the skin markings); (3) fibrillar pattern (comprises parallel fine fibrillar or filamentous pigmentation crossing the skin markings in a slanting direction) [1]; (4) other patterns which included: a) globular pattern (brown globules regularly distributed within the lesion), b) homogeneous pattern (light brown amorphous pigmentation), c) reticular pattern (black/brown network similar to the pigment network of non-glabrous skin) [2]; d) non-typical pattern (has no clearly defined pattern around the lesion and cannot be classified into the previous groups, there are no specific dermoscopic features of malignancy), e) multi-component pattern (has more than two different components with well-defined patterns), f) the parallel ridge pattern (band-like pigmentation following the ridges of skin markings) [1]. Globulostreak-like and transition patterns were not observed in our study.

In all included patients, the total body dermoscopic examination was also performed. For diagnosis of atypical nevi, we used the criteria proposed by Psaty et al. [10]: (1) $\geq 5 \mathrm{~mm}$ in size with a flat component and (2) $\geq 2$ of the following: (a) variable pigmentation, (b) irregular asymmetric border, and (c) indistinct border.

Congenital melanocytic nevi (CMN) were defined according to Alikhan et al. [11] as nevi that were present at birth or appeared within the first few weeks of life.

\section{Statistical analysis}

Continuous data were presented using mean along with standard deviation, as well as the minimum and maximum value. In addition, median values were provided with the lower and upper quartile. Categorical data were presented using rates and percentages. The relation between two qualitative values was assessed using the $\chi^{2}$ test and exact Fisher's test. The relation between two quantitative values was assessed using Pearson's or Spearman's correlation coefficient. Comparison between averages in several populations was based on the single-factor analysis of variance or Kruskal-Wallis test. Shapiro-Wilk test was used to assess the compliance between feature distribution and normal distribution, and Levene's test was used to assess the variance homogeneity. Results with $p<0.05$ value were considered to be statistically significant. Calculations were performed using R v.3.3.1 software.

\section{Results}

\section{Patients' characteristics}

Out of 713 patients, a group of 287 patients with acral nevi was selected. There were 624 melanocytic lesions on soles and palms identified. The studied group consisted of 174 (60.6\%) women and 113 (39.4\%) men with mean age of 43.5 years and 42.8 years, respectively. The youngest patient was 18 years old, and the oldest 81 years old. Most studied individuals (66.1\%) had higher education and lived in a city with more than 50,000 inhabitants (78\%) (Table 1).

\section{Skin phototype, nevi characteristics, personal and family history}

The majority of examined patients 168 (58.5\%) had the second skin phototype according to the Fitzpatrick's scale. As many as 115 (40.1\%) individuals had more than 100 nevi on their whole body. Interestingly, none had less 
than 20 nevi (Table 1). At least one atypical nevus was found in $247(86.1 \%)$ patients and in almost half of all studied individuals $140(48.8 \%)$ at least one congenital nevus was identified. One hundred and fifty (52.2\%) patients had a previous surgical excision of at least one melanocytic lesion. In 50 (17.4\%) cases, excised lesions were histopathologically diagnosed as malignant melanoma and in 100 (34.8\%) cases, the lesions were assessed as dysplastic ones. Forty-eight (16.7\%) patients reported family history of skin melanoma (first- and second-degree relatives) (Table 1).

\section{Awareness}

Out of all 164 patients with nevi localized only on the foot soles, 111 (68\%) were not aware of having them. Out of 44 patients with nevi present only on palms, 35 (79\%) patients did not know that they had them on palms. In a group of 79 patients with nevi present both on palms and soles, 60 (76\%) patients did not know that they had nevi on soles, 46 (58\%) did not know they had nevi on palms, $p=0.001$.

As many as 13 (4.5\%) patients reported that a general practitioner (GP) has performed at least once a full-body skin examination. Fifty-eight (20.2\%) patients claimed that only some nevi were assessed by a GP. Two hundred and sixteen (75.3\%) individuals reported that none of nevi have ever been assessed by a GP. Interestingly, 59 (83.1\%) of those 71 patients who had had all or some nevi checked, reported that soles and palms have never been examined by the GP.

One hundred and sixty-eight (58.5\%) of all patients reported that they had at least one full-body skin examination with dermoscopy done by a dermatologist. Ninety-two (32.1\%) reported that only some nevi and $27(9.4 \%)$ reported that none of nevi were examined. Eighty-seven (33.5\%) of 260 patients who had nevi checked, reported that soles and palms had never been examined by a dermatologist.

\section{Type of acral lesions, location and pattern analysis}

Six hundred and twenty-four nevi of 287 patients were examined. Four hundred and thirty-four (69.6\%) nevi were on the soles of the feet and 190 (30.4\%) were on palms of the hands. One hundred and twenty-two (42.5\%) patients had only one acral nevus, 77 (26.8\%) and 39 (13.6\%) had two and three, respectively. Fortynine (17\%) patients had four and more acral nevi. The mean \pm SD size of nevi on soles was $4.02 \pm 2.04 \mathrm{~mm}$ (min. $0.8 \mathrm{~mm}$, max. $12.3 \mathrm{~mm}$ ), on palms $2.37 \pm 1.21 \mathrm{~mm}$ (min. $0.7 \mathrm{~mm}$, max. $8.8 \mathrm{~mm}$ ); median (Q1-Q3) size of nevi on soles $3.6(2.6-5) \mathrm{mm}$, on palms $2.1(1.51-2.82) \mathrm{mm}$.

In 434 nevi present on foot soles, the following dermoscopic patterns were observed: parallel furrow 145 (33.4\%), lattice-like pattern 62 (14.3\%), fibrillar 66 (15.2\%) and other 161 (37.1\%), which included globular 17 (3.9\%),
Table 1. Patients' characteristics, skin phototype, nevi characteristics, personal and family history

\begin{tabular}{lc}
\hline Parameter & Number (\%) \\
\hline Total number of patients & $713(100)$ \\
\hline Total number of patients with an acral nevus & $287(40.2)$ \\
\hline Women: & \\
\hline Age: median 40 y (34-54); mean 43.5 $\pm 13.2 y$ & $174(60.6)$ \\
\hline Men: & $113(39.4)$ \\
\hline Age: median 40 y (34-48); mean 42.8 $\pm 13.1 y$ & \\
\hline Education: & $187(66.1)$ \\
\hline Higher & $82(29)$ \\
\hline Secondary & $14(4.9)$ \\
\hline Primary & $224(78)$ \\
\hline Place of living: & $63(22)$ \\
\hline City (> 50 000 inhabitants) & $19(6.6)$ \\
\hline Countryside & $168(58.5)$ \\
\hline Fitzpatrick skin phototype: & $93(32.4)$ \\
\hline I & $7(2.4)$ \\
\hline II & $115(40.1)$ \\
\hline III & $98(34.1)$ \\
\hline IV & $74(25.8)$ \\
\hline Number of patients with: & $247(86.1)$ \\
\hline$>100$ nevi on the body & $140(48.8)$ \\
\hline $50-100$ nevi on the body & $100(34.8)$ \\
\hline Pe-50 nevi on the body & \\
\hline Previoutives) & \\
\hline Previous nevi on the body & \\
\hline Melanoma in family (first-, second-degree & \\
\hline
\end{tabular}

homogeneous 9 (2.1\%), reticular 10 (2.3\%), non-typical 102 (23.5\%), parallel ridge pattern 3 (0.7\%), and multicomponent 20 (4.6\%).

In 190 nevi present on palms, the following dermoscopic patterns were observed: parallel furrow 117 (61.6\%), lattice-like pattern 44 (23.2\%) and other 29 (15.3\%), which included globular 13 (6.8\%), homogeneous $4(2.1 \%)$, reticular 2 (1.1\%), and non-typical 10 (5.3\%). Interestingly, no fibrillar and multi-component pattern among all palmar nevi were found (Table 2).

Additionally, an analysis of the location on palms and soles and dermoscopic pattern was performed. Out of 434 nevi present on the soles, 100 (23\%) were found on the weight-bearing area of the soles. In this location, the most common dermoscopic pattern was the fibrillar pattern which was found in 60 (60\%) nevi. In the arch region 
Table 2. Dermoscopic patterns of acral nevi

\begin{tabular}{|c|c|c|c|}
\hline Dermoscopic pattern & $\begin{array}{c}\text { Soles } \\
\text { Number (\%) } \\
N=434(69.6 \%)\end{array}$ & $\begin{array}{c}\text { Palms } \\
\text { Number (\%) } \\
N=190(30.4 \%)\end{array}$ & $\begin{array}{c}\text { Total } \\
\text { Number (\%) } \\
N=624(100 \%)\end{array}$ \\
\hline Parallel furrow: & $145(33.4)$ & $117(61.6)$ & $262(42)$ \\
\hline Single line & $87(20)$ & $69(36.3)$ & $156(25)$ \\
\hline Double line & $8(1.8)$ & $1(0.5)$ & $9(1.4)$ \\
\hline Single dotted line & $47(10.8)$ & $34(18)$ & $81(13)$ \\
\hline Double dotted line & $3(0.69)$ & $13(6.8)$ & $16(2.6)$ \\
\hline Lattice-like pattern & $62(14.3)$ & $44(23.2)$ & $106(17)$ \\
\hline Fibrillar & $66(15.2)$ & $0(0)$ & $66(11)$ \\
\hline Other: & $161(37.1)$ & $29(15.3)$ & $190(30)$ \\
\hline Globular & $17(3.9)$ & $13(6.8)$ & $30(4.8)$ \\
\hline Homogenous & $9(2.1)$ & $4(2.1)$ & $13(2.1)$ \\
\hline Reticular & $10(2.3)$ & $2(1.1)$ & $12(1.9)$ \\
\hline Non-typical & $102(23.5)$ & $10(5.3)$ & $112(18)$ \\
\hline Parallel ridge pattern & $3(0.7)$ & $0(0)$ & $3(0.5)$ \\
\hline Multi-component & $20(4.6)$ & $0(0)$ & $20(3.2)$ \\
\hline
\end{tabular}

Table 3. Location and dermoscopic patterns of acral nevi

\begin{tabular}{|c|c|c|c|c|c|c|}
\hline \multirow[t]{2}{*}{ Soles } & & \multicolumn{4}{|c|}{ Dermoscopic pattern } & \multirow[t]{2}{*}{$P$-value } \\
\hline & & $\begin{array}{l}\text { Other } \\
(n=161)\end{array}$ & $\begin{array}{l}\text { Lattice-like } \\
\qquad(n=62)\end{array}$ & $\begin{array}{l}\text { Parallel furrow } \\
\qquad(n=145)\end{array}$ & $\begin{array}{l}\text { Fibrillar } \\
(n=66)\end{array}$ & \\
\hline \multirow[t]{3}{*}{ Location } & $\begin{array}{l}\text { Other } \\
(n=248)\end{array}$ & $102(41.1 \%)$ & $24(9.7 \%)$ & 117 (47.2\%) & $5(2.0 \%)$ & $<0.001$ \\
\hline & $\begin{array}{c}\text { Arch } \\
(n=86)\end{array}$ & 35 (40.7\%) & 35 (40.7\%) & $15(17.4 \%)$ & $1(1.2 \%)$ & \\
\hline & $\begin{array}{l}\text { Weight-bearing area } \\
\qquad(n=100)\end{array}$ & $24(24 \%)$ & $3(3 \%)$ & $13(13 \%)$ & 60 (60\%) & \\
\hline \multirow{2}{*}{$\begin{array}{l}\text { Diameter } \\
{[\mathrm{mm}]}\end{array}$} & Mean \pm SD & $4.54 \pm 2.24$ & $3.49 \pm 1.48$ & $3.78 \pm 2.12$ & $3.78 \pm 1.5$ & $<0.001$ \\
\hline & Me (Q1-Q3) & $4.1(3-5.7)$ & $3.15(2.4-4.38)$ & $3.2(2.2-4.55)$ & $3.43(2.7-4.55)$ & \\
\hline \multirow[t]{2}{*}{ Palms } & & \multicolumn{4}{|c|}{ Dermoscopic pattern } & $P$-value \\
\hline & & $\begin{array}{l}\text { Other } \\
(n=29)\end{array}$ & $\begin{array}{l}\text { Latti } \\
\qquad(n\end{array}$ & & $\begin{array}{l}\text { Parallel furrow } \\
\quad(n=117)\end{array}$ & \\
\hline \multirow[t]{2}{*}{ Location } & $\begin{array}{c}\text { Palm } \\
(n=130)\end{array}$ & 15 (11.5\%) & \multicolumn{2}{|c|}{29 (22.3\%) } & $86(66.2 \%)$ & 0.072 \\
\hline & $\begin{array}{l}\text { Fingers } \\
(n=60)\end{array}$ & $14(23.3 \%)$ & \multicolumn{2}{|c|}{$15(25 \%)$} & 31 (51.7\%) & \\
\hline $\begin{array}{l}\text { Diameter } \\
{[\mathrm{mm}]}\end{array}$ & $\begin{array}{l}\text { Mean } \pm \text { SD } \\
\text { Me (O1-O3) }\end{array}$ & $\begin{array}{c}2.34 \pm 1.17 \\
2.20(1.70-2.6)\end{array}$ & \multicolumn{2}{|c|}{$\begin{array}{c}2.27 \pm 1.11 \\
2.10(1.53-2.7)\end{array}$} & $\begin{array}{c}2.42 \pm 1.27 \\
2.10(1.50-3.10)\end{array}$ & 0.837 \\
\hline
\end{tabular}

of the soles there were 86 (19.8\%) nevi, among which the lattice-like pattern was the most common one 35 (40.7\%) nevi. Interestingly, plantar nevi that had a lattice-like and parallel furrow pattern were smaller when compared to the other patterns $(p<0.001)$. One hundred and thirty (68.4\%) out of 190 palmar nevi were localized in the centre of the palms and the rest were on the digits. The most common pattern seen on the palms (regarding digital and central locations) was the parallel furrow pat- tern (Table 3). Forty-seven lesions were surgically excised, no acral malignant lesions were found.

Age and gender according to the diameter and dermoscopic pattern of the acral nevi

We found a significant correlation between age, gender and the diameter of the acral nevi. Men had significantly larger nevi on the soles than women (median $3.9 \mathrm{~mm}$ vs. $3.4 \mathrm{~mm} ; p=0.003$ ). There was also found a positive 
correlation between age and the diameter of the nevi on the soles $(p=0.02)$.

Nevi on the soles with a lattice-like pattern and parallel furrow pattern were smaller than those with other patterns (median 3.14 and 3.2 vs. 4.1 respectively; $p<0.001)$.

Correlation analysis between age and the dermoscopic pattern of nevi present on palms showed that younger individuals more frequently had the parallel furrow pattern in comparison to older patients who had significantly more frequently the lattice-like pattern (35 years of age and 42 years of age, respectively, $p<0.001)$.

\section{Location of acral nevi}

Patients with acral nevi present only on the soles were older than patients with nevi on the palms or both palms and soles $(p=0.029)$. By analysing the association between location of acral nevi and the total number of nevi on the body, it was found that patients with acral nevi present only on the soles and both palms and soles

Table 4. Location of acral nevi

\begin{tabular}{|c|c|c|c|c|c|}
\hline Parameter & $\begin{array}{c}\text { Soles } \\
(n=164)\end{array}$ & $\begin{array}{l}\text { Palms } \\
(n=44)\end{array}$ & $\begin{array}{l}\text { Soles AND palms } \\
\qquad(n=79)\end{array}$ & $\begin{array}{l}\text { Soles AND/OR palms } \\
\qquad(n=287)\end{array}$ & $P$-value \\
\hline Women/men & $\begin{array}{c}94 / 70 \\
57.3 \% / 42.7 \%\end{array}$ & $\begin{array}{c}27 / 17 \\
61.4 \% / 38.6 \%\end{array}$ & $\begin{array}{c}53 / 26 \\
67.1 \% / 32.9 \%\end{array}$ & $\begin{array}{c}174 / 113 \\
60.6 \% / 39.4 \%\end{array}$ & 0.345 \\
\hline \multicolumn{6}{|l|}{ Age [years]: } \\
\hline Mean \pm SD & $45 \pm 13.1$ & $40.4 \pm 13.4$ & $41.1 \pm 12.67$ & $43.2 \pm 13.15$ & \multirow[t]{2}{*}{0.029} \\
\hline Median (Q1-Q3) & $41(35-57)$ & $38(31-45)$ & $38(33-46)$ & $40(34-52)$ & \\
\hline \multicolumn{5}{|l|}{ Fitzpatrick: } & \multirow[t]{3}{*}{0.926} \\
\hline$I+I I$ & $106(64.6 \%)$ & $27(61.4 \%)$ & $54(68.4 \%)$ & $187(65.1 \%)$ & \\
\hline III + IV & $58(35.4 \%)$ & $17(38.6 \%)$ & $25(37.7 \%)$ & $100(34.8 \%)$ & \\
\hline Presence of atypical nevi on the body & $140(85.4 \%)$ & $36(81.8 \%)$ & 719 (89.9\%) & $247(86.1 \%)$ & 0.431 \\
\hline Presence of congenital nevi on the body & $79(48.2 \%)$ & $16(36.4 \%)$ & $45(57 \%)$ & $140(48.8 \%)$ & 0.088 \\
\hline \multicolumn{6}{|l|}{ Total body nevi count: } \\
\hline B 20-50 & B $43(26.2 \%)$ & В $15(34.1 \%)$ & B $16(20.3 \%)$ & B $74(25.8 \%)$ & \multirow[t]{3}{*}{0.043} \\
\hline C 50-100 & C $55(33.5 \%)$ & C $18(40.9 \%)$ & C $25(31.7 \%)$ & C $98(34.1 \%)$ & \\
\hline$D>100$ & D $66(40.2 \%)$ & D $11(25 \%)$ & D 38 (48.1\%) & D 115 (40.1\%) & \\
\hline Melanoma removal & $31(18.9 \%)$ & 7 (15.9\%) & $12(15.2 \%)$ & $50(17.4 \%)$ & 0.743 \\
\hline Dysplastic nevi removal & $54(32.9 \%)$ & $17(38.6 \%)$ & $29(36.7 \%)$ & $100(34.8 \%)$ & 0.717 \\
\hline \multicolumn{5}{|l|}{ Number of atypical nevi: } & \multirow[t]{3}{*}{0.011} \\
\hline Mean & 3.01 & 2.5 & 3.6 & 3.1 & \\
\hline Median & 3 & 2 & 3 & 3 & \\
\hline \multicolumn{5}{|l|}{ Number of acral nevi: } & \multirow[t]{3}{*}{$<0.001$} \\
\hline Mean & 1.8 & 1.4 & 3.3 & 2.2 & \\
\hline Median & 1 & 1 & 3 & 2 & \\
\hline
\end{tabular}

Table 5. Number of acral nevi and number of atypical nevi on the body

\begin{tabular}{lccc}
\hline Number of acral nevi & \multicolumn{1}{c}{ Number of atypical nevi on the body } & P-value \\
\cline { 2 - 4 } & $\begin{array}{c}0 \\
(n=40)\end{array}$ & $\begin{array}{c}1-4 \\
(n=199) \\
(n=48)\end{array}$ \\
\hline $\begin{array}{l}\text { Mean } \pm \text { SD } \\
\text { Median (Q1-Q3): }\end{array}$ & $1.8 \pm 1.11$ & $2.07 \pm 1.33$ & $2.94 \pm 1.67$ \\
\hline $\begin{array}{l}2 \\
(n=88)\end{array}$ & $11(12.5 \%)$ & $2(1-3)$ & $2.5(2-4)$ \\
\hline $\begin{array}{l}1-2 \\
(n=199)\end{array}$ & $29(14.6 \%)$ & $24(60.2 \%)$ & $24(12.1 \%)$ \\
\hline
\end{tabular}




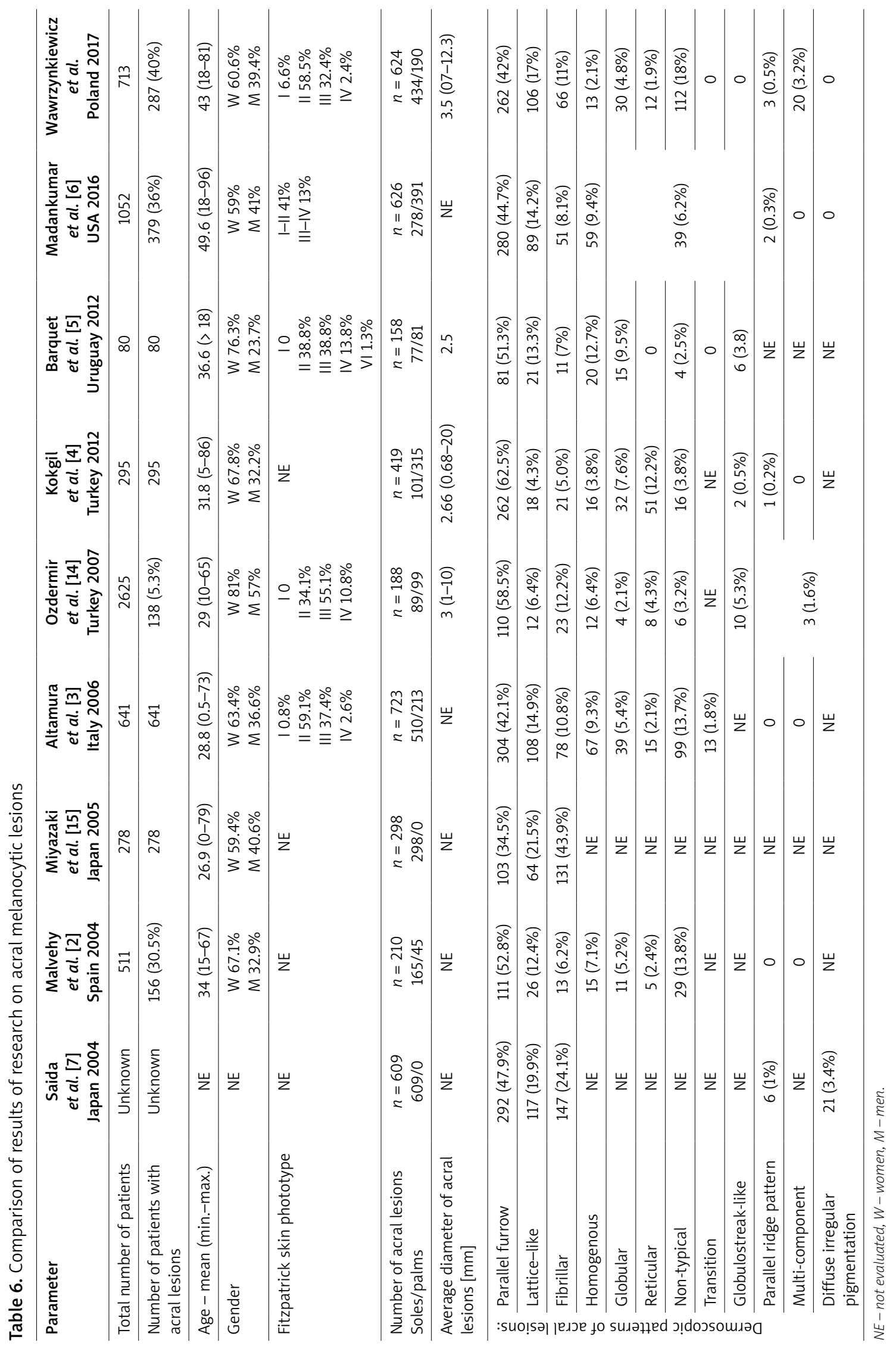


had a much higher total nevi count on the body when compared to patients with acral nevi present only on the palms $(p=0.043)$. Patients with acral nevi on the soles or both on the palms and soles had a higher number of atypical nevi on the body when compared to those with acral nevi only on the palms ( $p=0.011)$ (Table 4).

\section{Number of acral nevi}

Individuals with congenital nevi on the body 140 (48.8\%) had significantly more acral nevi (median 2 vs. 1 , $p=0.004$ ). By analysing the association between acral nevi and the total number of nevi on the body, it was found that the number of acral nevi increased along with the total number of nevi on the body $(p<0.001)$.

We found a significant correlation between the number of acral nevi and the number of atypical nevi on the body ( $p=0.001)$. Individuals with a higher number of atypical nevi on the body had a higher median and mean number of acral nevi. Moreover, a positive correlation between the number of acral nevi and the number of atypical nevi on the body was found $(p=0.006)$ (Table 5).

\section{Discussion}

The first researchers who studied acral melanocytic lesions using dermoscopy were Saida et al. [12]. They described specific dermoscopic patterns associated with benign lesions such as the parallel furrow, lattice-like and fibrillar pattern. On the other hand, the parallel ridge pattern, irregular diffuse pigmentation or multi-component pattern and presence of local features such as: peripheral dots/globules, abrupt edges were associated with malignancy $[1,13]$.

Subsequent studies of acral nevi performed by Malvehy and Puig, Altamura et al., Kogkil et al., Ozdemir et al. showed similar results. However, significant differences in frequencies of specific patterns were noticed $[2-4,14]$. We present a comparison of the mentioned studies in Table 6 . Detailed analysis of these studies demonstrated significant differences in patients' selection (inclusion of only selected patterns in the analysis, specifics of the study group selection, such as age or phenotype features). Several studies described dermoscopic patterns observed in acral nevi. Malvehy and Puig [2] described the homogeneous, globular and reticular patterns. Altamura et al. [3] described the transition pattern. Ozdemir et al. [14] described the globulostreak-like pattern. In the Spanish population, a higher incidence of acral nevi with a non-typical pattern was found, as compared to Japanese studies [2]. On the other hand, in the Turkish population, it was found that the incidence of patterns other than parallel furrow, lattice-like, fibrillar pattern was even higher $[4,14]$.

Our study was the first one that showed the dermoscopic patterns of acral nevi in the Polish population. The parallel pattern was the most common dermoscopic pattern observed in the analysed population, with the non-typical one being the second. A high incidence of non-typical patterns is a feature that distinguishes the results obtained by us from the results of studies conducted in different populations.

Mean patient age in our study was 43 years and was significantly higher when compared to other studies which patients under the age of 18 were included.

Our research showed that older patients compared to younger patients had a significantly higher diameter of nevi.

In the Polish population, the lattice-like pattern was most commonly found in the arch region, and the fibrillar pattern in the weight-bearing area of the soles. These results were similar to the results of Kokgil et al. [4], Ozdemir et al. [14], and Miyazaki et al. [15].

Over the course of the study, we found that people with atypical nevi on the body and people who have a high number of nevi on the body, also presented a higher number of acral nevi. One of the most interesting findings of our study was a positive correlation between the number of acral nevi and the number of atypical nevi on the body. People with a higher number of atypical nevi on the body had a higher number of acral nevi. The presence of atypical nevi and a high number of nevi on the body are the risk factors of melanoma. Because of that it is possible to note that a higher number of acral nevi should increase diagnostic alertness. This association requires further studies on a larger group of patients.

A very interesting finding in our study, similar to the US studies [6], was the fact that most patients did not know they had nevi in the acral area. Moreover, patients stated that general practitioners and dermatologists often did not examine their palms and soles during doctors' visits. It seems significant to draw medical community's attention to the presence of acral nevi, which may ensure earlier detection and treatment initiation.

\section{Conclusions}

Our study demonstrated a higher incidence of acral nevi when compared to the other populations. In the examined population, as much as $40.2 \%$ of patients had acral nevi, whereas in other studies which included the Caucasian population, the incidence of acral nevi was approx. 30\%.

\section{Conflict of interest}

The authors declare no conflict of interest.

\section{References}

1. Saida T, Oguchi S, Miyazaki A. Dermoscopy for acral pigmented lesions. Clin Dermatol 2002; 20: 279-85.

2. Malvehy J, Puig S. Dermoscopic patterns of benign volar melanocytic lesions in patients with atypical mole syndrome. Arch Dermatol 2004; 140: 538-44. 
3. Altamura D, Zalaudek I, Sera F, et al. Dermoscopic changes in acral melanocytic nevi during digital follow-up. Arch Dermatol 2007; 143: 1372-6.

4. Kokgil TD, Ekmekci TR, Yasar S. Videodermoscopic pattern analysis of acral melanocytic nevi. J Dermatol 2012; 39: 290-4.

5. Barquet V, Dufrechou L, Nicoletti S, et al. Dermoscopic patterns of 158 acral melanocytic nevi in a Latin American population. Actas Dermosifiliogr 2013; 104: 586-92.

6. Madankumar R, Gumaste PV, Martires K, et al. Acral melanocytic lesions in the United States: prevalence, awareness, and dermoscopic patterns in skin-of-color and non-Hispanic white patients. J Am Acad Dermatol 2016; 74: 724-30.

7. Saida T, Miyazaki A, Oguchi S, et al. Significance of dermoscopic patterns in detecting malignant melanoma on acral volar skin. Arch Dermatol 2004; 140: 1233-8.

8. Kuchelmeister C, Schaumburg-Lever G, Garbe C. Acral cutaneous melanoma in caucasians clinical features, histopathology and prognosis in 112 patients. Br J Dermatol 2000; 143: 275-80.

9. Czerwinska M, Alekseenko A, Rup E, et al. Retrospective data analysis of the history of patients treated for malignant melanoma at the Department of Dermatology, Jagiellonian University between 1991 and 2008. Post Dermatol Alergol 2011; 28: 92-6.

10. Psaty EL, Scope A, Halpern AC, Marghoob AA. Defining the patient at high risk for melanoma. Int J Dermatol 2010; 49: 362-76.

11. Alikhan A, Ibrahimi OA, Eisen DB. Congenital melanocytic nevi: where are we now? Part I. Clinical presentation, epidemiology, pathogenesis, histology, malignant transformation, and neurocutaneous melanosis. J Am Acad Dermatol 2012; 67: 495.e1-17.

12. Saida T, Koga H, Uhara H. Key points in dermoscopic differentiation between early acral melanoma and acral nevus. J Dermatol 2011; 38: 25-34.

13. Saida T, Oguchi S, Ishihara Y. In vivo observation of magnified features of pigmented lesions on volar skin using videomicroscope: usefulness of epiluminescence technique in clinical diagnosis. Arch Dermatol 1995; 131: 298-304.

14. Ozdemir F, Karaarslan IK, Akalin T. Variations in the dermoscopic features of acquired acral melanocytic nevi. Arch Dermatol 2007; 143: 1378-84.

15. Miyazaki A, Saida T, Koga H, et al. Anatomical and dermoscopic patterns seen in melanocytic nevi on the soles: a retrospective study. J Am Acad Dermatol 2005; 53: 230-6. 